\title{
Formation of functional areas in the cerebral cortex is disrupted in a mouse model of autism spectrum disorder
}

\author{
Laura R Fenlon', Sha Liư', Ilan Gobius ${ }^{1}$, Nyoman D Kurniawan², Skyle Murphy', Randal X Moldrich,4 \\ and Linda J Richards ${ }^{1,3^{*}}$
}

\begin{abstract}
Background: Autism spectrum disorders (ASD) are a group of poorly understood behavioural disorders, which have increased in prevalence in the past two decades. Animal models offer the opportunity to understand the biological basis of these disorders. Studies comparing different mouse strains have identified the inbred BTBR $T+t f / J$ (BTBR) strain as a mouse model of ASD based on its anti-social and repetitive behaviours. Adult BTBR mice have complete agenesis of the corpus callosum, reduced cortical thickness and changes in early neurogenesis. However, little is known about the development or ultimate organisation of cortical areas devoted to specific sensory and motor functions in these mice that may also contribute to their behavioural phenotype.
\end{abstract}

Results: In this study, we performed diffusion tensor imaging and tractography, together with histological analyses to investigate the emergence of functional areas in the cerebral cortex and their connections in BTBR mice and age-matched C57BI/6 control mice. We found evidence that neither the anterior commissure nor the hippocampal commissure compensate for the loss of callosal connections, indicating that no interhemispheric neocortical connectivity is present in BTBR mice. We also found that both the primary visual and somatosensory cortical areas are shifted medially in BTBR mice compared to controls and that cortical thickness is differentially altered in BTBR mice between cortical areas and throughout development.

Conclusions: We demonstrate that interhemispheric connectivity and cortical area formation are altered in an age- and region-specific manner in BTBR mice, which may contribute to the behavioural deficits previously observed in this strain. Some of these developmental patterns of change are also present in human ASD patients, and elucidating the aetiology driving cortical changes in BTBR mice may therefore help to increase our understanding of this disorder.

Keywords: Autism spectrum disorders (ASD), BTBR mice, Agenesis of the corpus callosum, Cortical area patterning, Diffusion imaging

\section{Background}

Autism spectrum disorders (ASD) represent a group of behaviourally defined neurodevelopmental disorders associated with disruptions of social, cognitive and/or motor behaviours. Increased understanding and acceptance of ASD in recent clinical practice indicates that the prevalence of ASD has reached a median rate of 13/10,000 in

\footnotetext{
*Correspondence: richards@uq.edu.au

'Queensland Brain Institute, The University of Queensland, Building 79,

St Lucia Campus, Brisbane, QLD 4072, Australia

${ }^{3}$ The School of Biomedical Sciences, The University of Queensland, St Lucia Campus, Brisbane, QLD 4072, Australia

Full list of author information is available at the end of the article
}

young children, or even $1 \%$ in certain populations, with a male/female ratio of 4.4:1 [1]. However, although it is suggested that the complex impairments observed in ASD patients are caused by a number of genetic and environmental factors, as well as immunological and metabolic status, the neurological aetiology of ASD remains unclear [2-9]. Previous neuroimaging studies have revealed several conserved anatomical alterations in autistic patients that may be relevant to their behavioural abnormalities [10]. These include increased total brain volume, decreased grey matter volume in the amygdala-hippocampal complex, 
a thinner corpus callosum and malformations of the ventricular system [11-13].

Although autism is a human disorder, some of its characteristic behavioural phenotypes can be modelled in animals, facilitating experimental investigations of the anatomical and functional abnormalities that may be associated with ASD [14-18]. BTBR $\mathrm{T}+\mathrm{tf} / \mathrm{J}$ (BTBR) is an inbred mouse strain that displays robust behavioural phenotypes analogous to the three major diagnostic criteria of autism: aberrant reciprocal social interactions, deficits in social communication and repetitive stereotypic behaviours $[14,19,20]$. Neuroanatomical studies using magnetic resonance imaging (MRI) and diffusion tensor MRI have demonstrated that BTBR mice display anatomical abnormalities that include volume changes in the cerebral white matter and grey matter and disruptions in the major white matter tracts of the brain $[16,17,21,22]$. Most of these studies have focused on white matter malformations, revealing complete agenesis of the corpus callosum, thinning of the hippocampal commissure and the presence of ectopic interhemispheric connectivity above the third ventricle [16], subcortically through the posterior cerebrum [21] and excessively through the anterior commissure [17]. However, despite the ASD-like traits commonly exhibited by humans with agenesis of the corpus callosum [23], the behavioural trait of low sociability in mouse models does not appear to be related to the presence or size of this commissure [24,25], indicating that other developmental changes in the brain may be associated with this trait.

Recent data from genetic studies of human autistic patients have suggested that genes regulating the formation of the cortical areas specialised for the processing of sensory or motor information could be affected in ASD patients [26-28]. Our knowledge of how cortical areas are formed is primarily based on gene expression and mutational analyses in mice. However, whether BTBR mice display malformations in the formation of cortical sensory areas or their region-specific connections is unknown.

In this study, we investigated the development of cortical areas and neocortical interhemispheric connectivity in BTBR mice compared with $\mathrm{C} 57 \mathrm{Bl} / 6$ mice. The inbred $\mathrm{C} 57 \mathrm{Bl} / 6$ mouse strain is commonly used as a control for studies in BTBR mice as it displays high sociability and low repetitive self-grooming behaviours [19]. Diffusion MRI and tractography were used to examine interhemispheric connectivity and confirmed the complete absence of the corpus callosum and a thinner hippocampal commissure in the BTBR mice. However, neither the anterior commissure nor the hippocampal commissure appears to anatomically compensate for the loss of callosal connections in these mice. In addition, protein expression analyses and measurements were conducted to investigate the formation of sensory areas in the cerebral cortex and area-specific connections. We found that the thickness and size of the cortical areas is altered in a region- and age-dependent manner, and both the primary somatosensory (S1) and primary visual (V1) cortical areas are shifted medially in BTBR mice. These findings provide an increased understanding of developmental changes in the cortex of an animal model of ASD and add to our current knowledge of the pathophysiological processes that may potentially occur in this developmental disorder.

\section{Results}

BTBR mice display a severe neocortical interhemispheric disconnection

The anterior commissure, the hippocampal commissure and the corpus callosum are the three major commissural tracts present in the mouse and human forebrain. Although it is clear that BTBR mice have complete agenesis of the corpus callosum [22], the extent of neocortical disconnection through other commissures remains unclear. Results from previous investigations of telencephalic commissures in the BTBR mouse have been inconsistent, with some finding novel ectopic tracts connecting the cortical hemispheres $[16,21]$, and others finding an increase in fibres crossing through the anterior commissure [17]. To examine these axon tracts and the degree of interhemispheric connectivity in three dimensions in mice, we performed diffusion MRI and tractography on adult BTBR and C57Bl/6 brains $(n=6$ for each strain).

In the C57Bl/6 mice, the callosal axons constitute a long band of axons in the sagittal plane projecting across the midline (white arrow in Figure 1A). We first confirmed that the corpus callosum in BTBR mice is absent at the midline in the sagittal view (white arrow in Figure 1B). It has been demonstrated that in animals and humans with callosal malformations, callosally projecting axons aggregate on either side of the midline to form longitudinal axon bundles called Probst bundles [29-32]. In accordance with previous results $[16,17,25,33]$, we demonstrated that Probst bundles are present on both sides of the midline in $100 \%$ of cases in coronal planes of BTBR brains (white circles in Figure 1F), but not in any of the $\mathrm{C} 57 \mathrm{Bl} / 6$ brains (Figure 1E). By selecting a region of interest (ROI) in the corpus callosum of $\mathrm{C} 57 \mathrm{Bl} / 6$ mice (white box in Figure 1E) we observed that streamlines generated through this ROI run mediolaterally, crossing the midline and connecting the left and right cortices (Figure 1G), whereas streamlines generated from ROIs of the Probst bundles (white circles in Figure 1F, with 10,000 streamlines generated from these ROIs) form longitudinal tracts, which project caudally towards the hippocampus or ventrally to the basal forebrain (Figure $1 \mathrm{H}$ ), as previously described in other acallosal mouse strains $[32,34]$. 

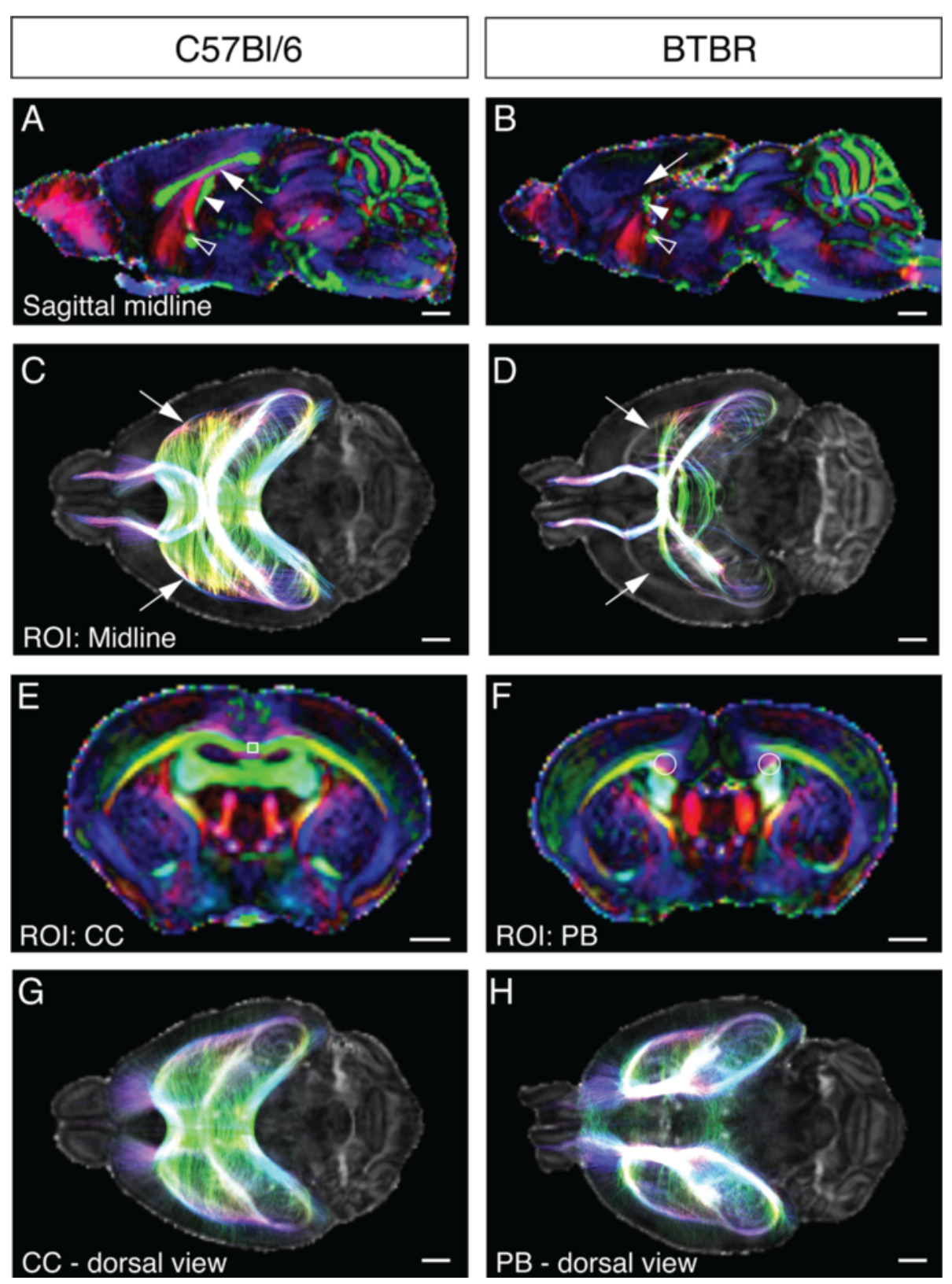

Figure 1 Agenesis of the corpus callosum and Probst bundle formation in adult BTBR mice. (A, B) Representative colour fractional anisotropy maps in a mid-sagittal plane of adult C57BI/6 and BTBR mouse strains. Absence of the corpus callosum can be observed in BTBR mice (white arrow in (B)). A partial remnant of the hippocampal commissure is present in the BTBR mice (white arrowhead in (B)). The anterior commissure is preserved and is in a similar position in both mouse strains (open arrowheads in (A) and (B)). (C, D) Representative dorsal views of the tractography shows a large region of dispersed green streamlines connecting the two sides of the brain in C57BI/6 mice (white arrows in (C)), whereas in BTBR mice this is absent (white arrows in (D)). In the coronal plane $\mathbf{( E ,} \mathbf{F})$, the corpus callosum is formed in C57BI/6 mice, whereas Probst bundles are present on both sides of the midline in BTBR mice (white circles in (F)). All callosal streamlines passing through the corpus callosum at the midline (white box in (E)) are shown in (G), and all streamlines passing through the Probst bundle in each hemisphere are shown in $\mathbf{( H )}$. The fibres within the Probst bundles run rostrocaudally, connecting hippocampal and basal forebrain regions. Orientations for the colour fractional anisotropy maps: red, rostrocaudal; green, mediolateral; blue, dorsoventral. Scale bar $=1 \mathrm{~mm}$. ROI = region of interest; $C C=$ corpus callosum, $\mathrm{PB}=$ Probst bundles; $\mathrm{BTBR}=\mathrm{BTBR} T+\mathrm{tf} / \mathrm{J}$.

Next, we investigated the degree of connectivity of the other traditional cortical commissures in BTBR mice, first confirming previous findings that the hippocampal commissure is present but greatly reduced in size in the
BTBR strain $(7,639 \pm 1,015$ streamlines in BTBR mice compared to $9,441 \pm 100$ streamlines in $\mathrm{C} 57 \mathrm{Bl} / 6$ mice, $P=0.0072$ Student's $t$-test; white arrowhead in Figure 1B, and Figure 2E,G). However, contrary to previous reports 


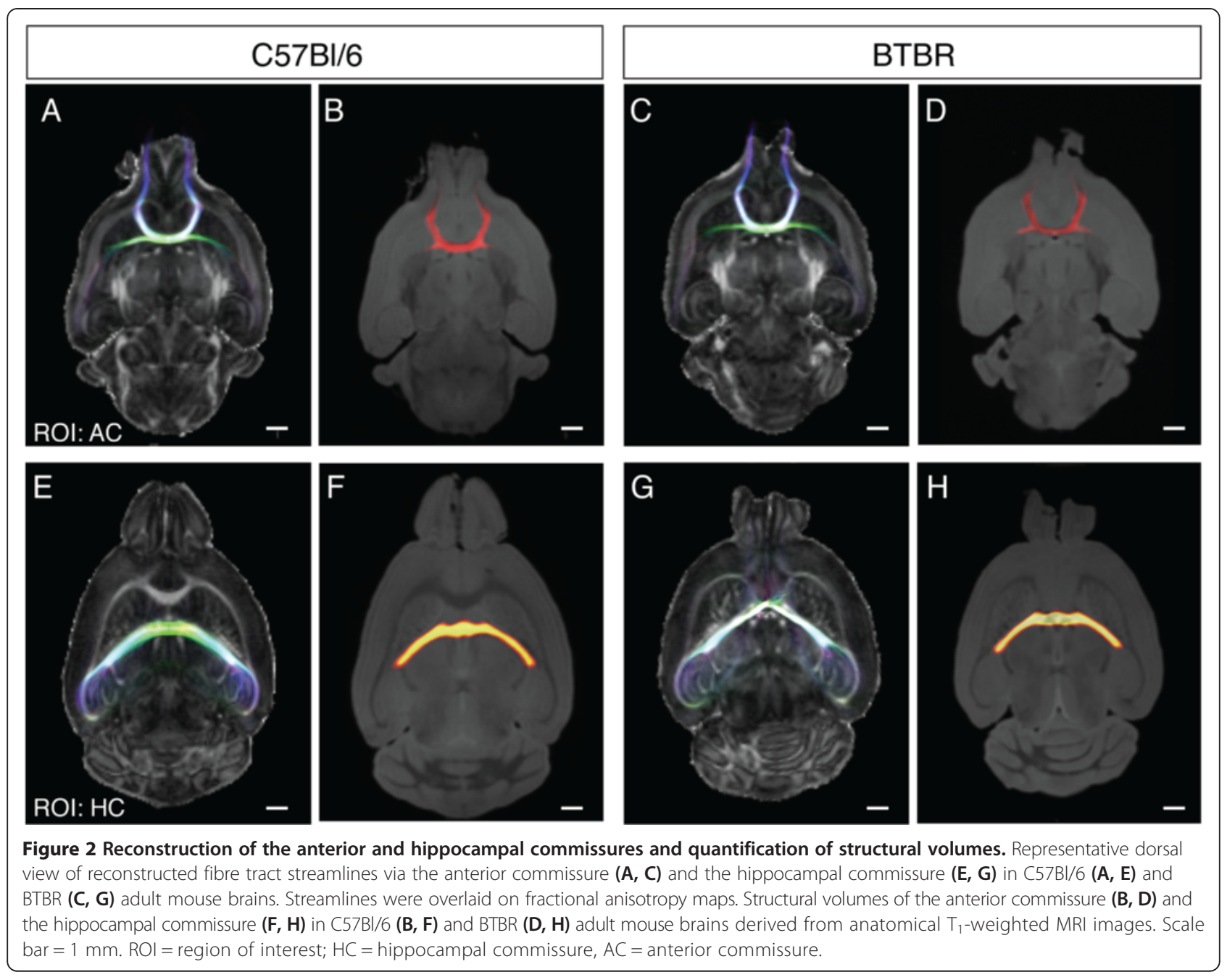

[17], we found that the anterior commissure is preserved, but not enlarged (but rather reduced) in the BTBR strain $(8,612 \pm 548$ streamlines in BTBR mice compared to $9,587 \pm 409$ streamlines in $\mathrm{C} 57 \mathrm{Bl} / 6$ mice, $P=0.0065$ Student's $t$-test; open arrowheads in Figure $1 \mathrm{~A}, \mathrm{~B}$ and Figure 2A,C). Similarly, by measuring the volume of each of these commissures from our 3D MRI data (normalised to the size of the brain; $n=6$ for each strain; Figure 2B,D,F,H), we found that the volume of both the anterior $(0.73 \pm 0.02 \%$ in $\mathrm{C} 57 \mathrm{Bl} / 6$ and $0.67 \pm 0.01 \%$ in BTBR mice, $P=0.0008$, Student's $t$-test) and hippocampal $(0.53 \pm 0.03 \%$ in $\mathrm{C} 57 \mathrm{Bl} / 6$ and $0.42 \pm 0.02 \%$ in BTBR mice, $P=0.0001$, Student's $t$-test) commissures are significantly reduced in BTBR mice.

The lack of enlargement of the anterior and hippocampal commissures in the BTBR strain does not conclusively exclude the possibility of abnormal neocortical connectivity, as axons from cortical regions normally connected by the callosum could reroute through these commissures at the expense of the areas that they usually connect. To address whether specific functional cortical areas are connected via the anterior commissure or hippocampal commissure in BTBR mice, ROIs were placed in the bilateral motor, somatosensory and visual areas of the cortex in both $\mathrm{C} 57 \mathrm{Bl} / 6$ and BTBR brains, and tractography was performed with inclusion ROIs in each commissure. Our results revealed that, within 10,000 streamlines generated through each commissure, there are no significant streamline connections between homologous interhemispheric areas via the anterior or hippocampal commissure in BTBR compared to $\mathrm{C} 57 \mathrm{Bl} / 6$ mice. Together, these results show that neither the anterior commissure nor the hippocampal commissure compensates for the loss of callosal connections between functionally similar neocortical interhemispheric areas in BTBR mice.

Finally, we investigated the presence of ectopic interhemispheric connectivity in the BTBR strain by reconstructing all of the axons crossing the midline. We observed elaborate connections between the two hemispheres in $\mathrm{C} 57 \mathrm{Bl} / 6$ mice, including between the bilateral olfactory bulbs, cortices and hippocampi (Figure 1C). 
However, contrary to previous reports showing ectopic neocortical commissures in the BTBR strain [16,21], we found that streamlines connecting the two cortices are absent in these mice (compare white arrows in Figure 1C,D), leaving only streamlines connecting the two olfactory bulbs via the anterior commissure and the hippocampi via the hippocampal commissure. Collectively, these results show that the neocortices of BTBR mice are not connected by the corpus callosum, through other forebrain commissures, nor via ectopic forebrain connections.

\section{The size and position of primary neocortical areas is altered in BTBR mice}

It is possible that the absence of neocortical interhemispheric connectivity in BTBR mice may have subsequent effects on the postnatal development of the neocortex, as callosal axons no longer innervate their normal targets $[35,36]$. Therefore, we next investigated whether the formation of neocortical areas, particularly in terms of their topographic organisation and relative positions along the medial-lateral and anterior-posterior axes, is altered in BTBR mice. As S1 (blue arrowheads in Figure 3) and V1 (magenta arrowheads in Figure 3 ) are the most readily identifiable primary neocortical areas in mice, we focused on the formation and position of these areas at different postnatal stages (P7, P10 and P22), using anti-v-Glut2 immunohistochemistry in tangential sections to visualise the axons terminals of glutamatergic neurons within layer 4 $[37,38]$. All cortical arealisation measurements were performed blind using de-identified images.

When we investigated the shape and number of individual barrels within $\mathrm{S} 1$, we observed no difference between BTBR and $\mathrm{C} 57 \mathrm{Bl} / 6$ brains at any of the examined stages (blue arrows in Figure 3A,B,D,E,F,G; $n \leq 6$ for each strain). We next analysed the spatial position of the posterior medial barrel subfield (PMBSF) with respect to its position in the anterior-posterior and medial-lateral axes of the cortex (schematics shown in Figure $3 \mathrm{C}, \mathrm{H}$ ), as the topography of this structure is highly conserved across different mouse strains [39]. Specifically, the spatial position of the PMBSF within the neocortex was determined by identifying the position of the third barrel in row $\mathrm{C}$ ( $\mathrm{C} 3$ barrel; highlighted in red in Figure $3 \mathrm{C}, \mathrm{H})$. These measurements revealed that the $\mathrm{C} 3$ barrel is located in a more medial relative position in BTBR brains than in $\mathrm{C} 57 \mathrm{Bl} / 6$ brains at all ages examined (Figure 3I and Additional file 1). Furthermore, the anterior-posterior position of the C3 barrel is relatively similar in both strains, except in P22 BTBR mice, where it is shifted significantly anteriorly (Figure 3I and Additional file 1).

Further measurements revealed that the total cortical area is similar in $\mathrm{C} 57 \mathrm{Bl} / 6$ and BTBR mice at P10 and P22 ( $n=8$ for each strain), yet the length of the BTBR cortex is reduced at P10, and the width is reduced at
$\mathrm{P} 22$. In addition, the relative size of the PMBSF is reduced at P10, and similarly, the relative size of the visual area is significantly reduced at both P10 and P22 (Figure 3I and Additional file 1), perhaps indicating fluctuations in the rate at which different cortical areas grow in BTBR brains compared to controls.

Together, our results indicate that V1 is reduced in size relative to the total cortical area in BTBR mice, which may impact the relative position of S1. Moreover, the relative positions of both the PMBSF and V1 are generally normal along the anterior-posterior axis at most postnatal ages but are significantly shifted towards the midline in BTBR mice at all stages of development, irrespective of changes in cortical size.

\section{BTBR mice display altered cortical thickness at different developmental stages that is not due to changes in the relative proportion of specific cortical layers}

Given the observed changes in the size and position of cortical areas of BTBR mice, we next investigated whether BTBR brains also display alterations in the formation and lamination of the cortical plate. It has been reported that the proliferation, migration and apoptosis of cortical neurons may be altered in BTBR mice $[40,41]$, which may subsequently influence the final distribution of neurons in different cortical layers. To examine this further, we first assessed the absolute thickness of the cortex (in the coronal plane), and the relative proportion of cortical layers in early postnatal and adult animals, in two cortical areas (S1 and V1) using nuclear staining analysis (Figure 4; Additional file 2). We found that the thickness of V1 in BTBR brains is significantly increased compared to that of $\mathrm{C} 57 \mathrm{Bl} / 6$ mice at P7 $(P=0.0002$, Student's $t$-test $)$ whereas that of S1 is unchanged (Figure $4 \mathrm{~A}, \mathrm{~B}, \mathrm{C} ; n=7$ for both strains). Interestingly, we found that this trend is altered in adult animals, such that the thickness of $\mathrm{S} 1$ and V1 is not significantly different between the two strains, although there is a trend towards a reduced thickness in the BTBR mouse (Figure 4E,F,G; $n=6$ for both strains). The relative thickness of the layers that make up the cortex in the above measurements does not differ significantly between strains for either S1 or V1 across ages (Figure 4D,H), suggesting that the changes in cortical thickness are due to a generalised increase or decrease in all cortical layers.

\section{Altered cortical size in BTBR mice may be due to a change in global cell number, rather than changes in specific neuronal populations or apoptotic pathways}

To further investigate the cellular processes underlying these developmental changes in BTBR cortical size, we then assessed the laminar organisation present within S1 and V1 during development. Both strains were analysed with immunohistochemistry for three different cortical 

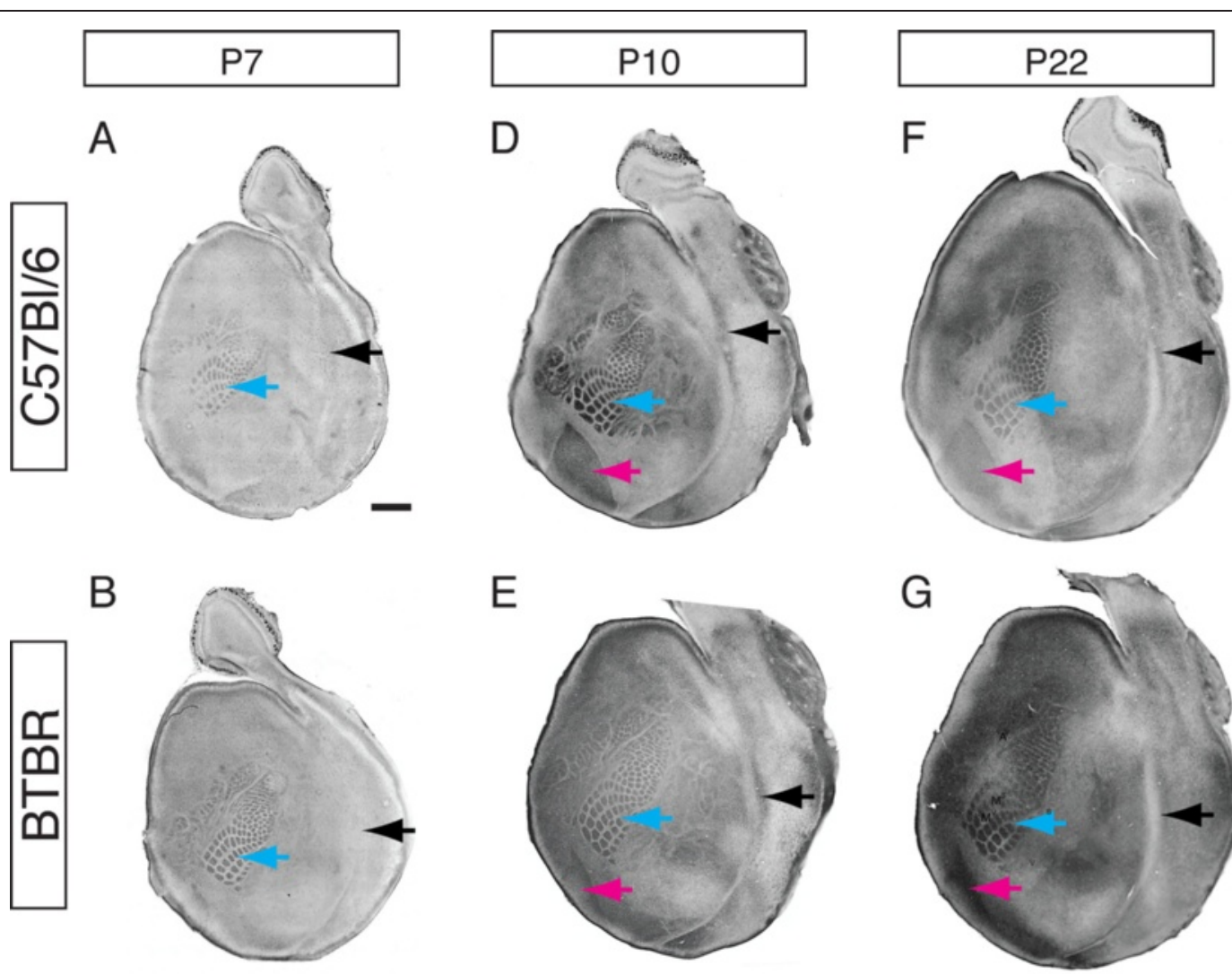

E
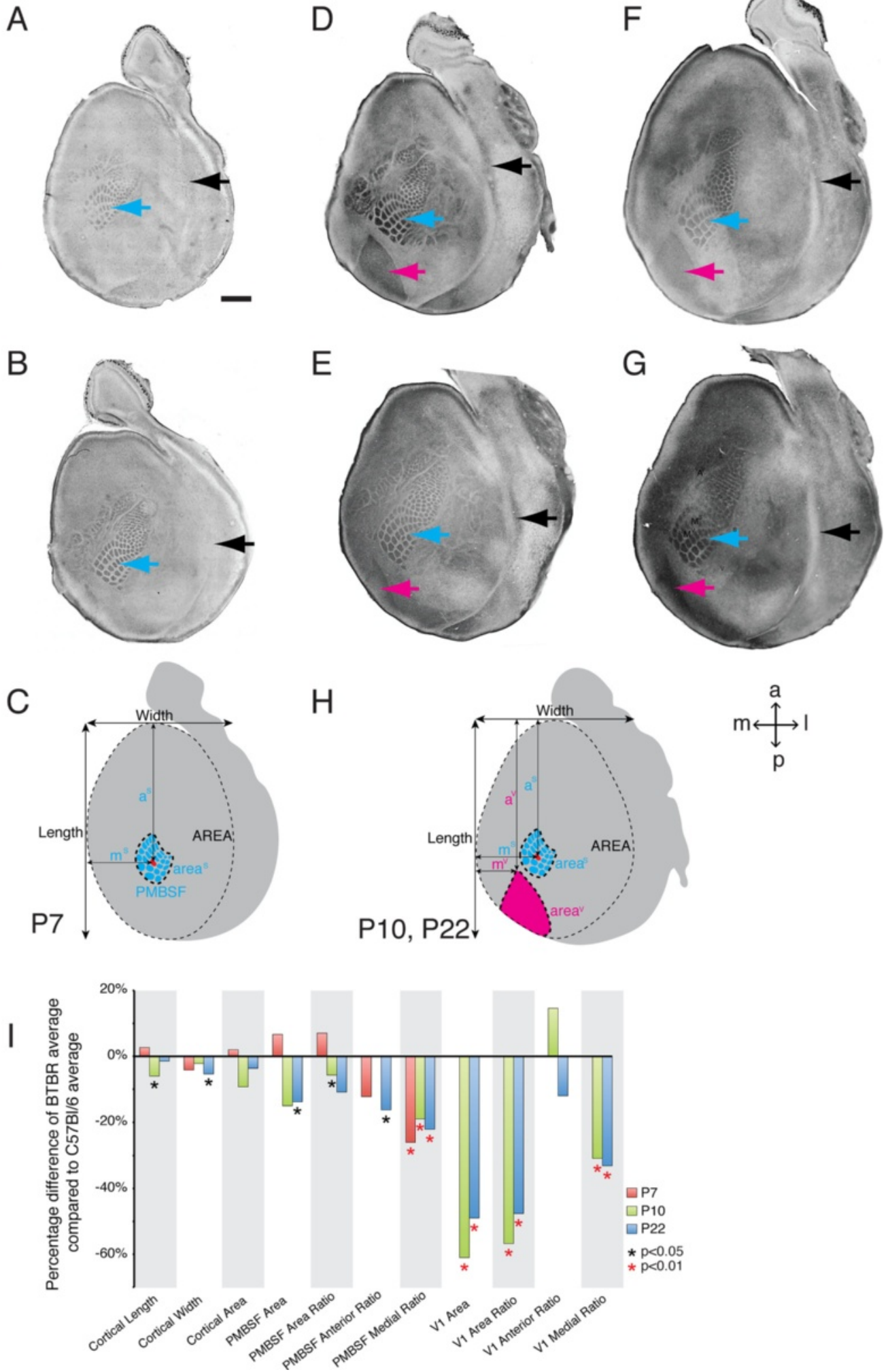

Figure $\mathbf{3}$ (See legend on next page.) 


\section{(See figure on previous page.)}

Figure 3 Medially shifted somatosensory and visual areas and a reduction in primary visual area in developing BTBR mice. Tangential sections through layer 4 of flattened cortices stained for anti v-Glut2 were obtained from P7 (A, B), P10 (D, E) and P22 (F, G) C57Bl/6 (A, D, F) and $\operatorname{BTBR}(\mathbf{B}, \mathbf{E}, \mathbf{G})$ mice ( $n \geq 6$ for each age and strain). V-Glut2-positive PMBSF barrels in S1 at P7, P10 and P22 are indicated with blue arrows, and the V-Glut2-positive $\mathrm{V} 1$ is indicated by magenta arrows; the rhinal fissure (demarcating the border between neocortex and olfactory cortex) is indicated by black arrows. (C, H) Schematics of P7 (C) or P10 and P22 tangential sections (H) illustrate the cortical arealisation parameters that were measured in BTBR and C57BI/6 mice. (I) Quantification of the cortical arealisation parameters in both strains, including total cortical length, width and area; total PMBSF area; PMBSF area normalised to total cortical area; PMBSF position relative to the anterior extent of the cortex; PMBSF position relative to the medial extent of the cortex; total $\mathrm{V} 1$ area; $\mathrm{V} 1$ area normalised to total cortical area; $\mathrm{V} 1$ position relative to the anterior extent of the cortex; and V1 position relative to the medial extent of the cortex. Measurements relating to V1 arealisation were only obtained at P10 and P22, as the V1 area is indistinct at P7 in tangential sections. Measurements were averaged for each strain and displayed as the percentage difference between BTBR and C57BI/6 (100\%). Orientations of tangential sections are indicated in the upper right corner of (H): anterior/rostral to the top, posterior/caudal to the bottom, medial to the left and lateral to the right. Scale bar $=1 \mathrm{~mm}, \mathrm{BTBR}=\mathrm{BTBR} T+\mathrm{tf} / \mathrm{J}, \mathrm{PMBSF}=$ posterior medial barrel subfield.

layer markers at P7 (Figure 5A,B,C,D; $n=7$ for each strain). These markers were as follows: special AT-rich sequence-binding protein 2 (Satb2), which is expressed by cortical neurons in layers $2 / 3$ and is essential for the development of callosal projections [42-44]; chicken ovalbumin upstream promoter transcription factor-interacting protein 2 (Ctip2), which is a marker of subcortically projecting neurons in layer $5[45,46]$; and T-box brain gene 1 (Tbr1) which is expressed in early-born glutamatergic cortical neurons in layer 6 and is important for the formation of the subplate and layer 6 [47]. We found that the distribution patterns of neuronal populations positive for Satb2, Ctip2 and Tbr1 in both S1 and V1 are similar in BTBR and control animals at P7 (Figure $5 \mathrm{~A}, \mathrm{C}$ ), indicating that cortical lamination at a gross level is not disrupted in BTBR mice. Furthermore, the total number of labelled cells per $500 \mu \mathrm{m}$ of cortex is not significantly different between strains within either S1 or V1 (Figure 5B,D; Additional file $3 ; n=7$ for each strain). This indicates that the changes in cortical thickness exhibited by BTBR animals are not due to an increase in cell number of a specific cortical laminar population. Alternatively, a change in cortical thickness could also be due to differences in cellular apoptosis between strains. To investigate this, the average number of Caspase3-labelled cells within $500 \mu \mathrm{m}$ of developing cortex was quantified ( $n=7$ for each strain). This revealed that the number of Caspase3-positive cells (green in Figure $5 \mathrm{E}$ ) is unchanged between the two strains at P7 (Figure 5E,F; Additional file 3), indicating that developmental changes in cortical thickness are not due to alterations in apoptotic pathways. Finally, in order to determine whether the change in cortical thickness of BTBR brains is due to a change in cortical cell density, rather than a general increase in cell number, we quantified the density of DAPI-stained nuclei per $1 \mathrm{~mm}^{2}$ of cortex ( $n=7$ animals for each strain). Despite the increase in cortical thickness in V1 of BTBR animals at P7, we did not find a significant difference in cell density between the two strains in either S1 (Figure 5G) or V1 (Figure 5H;
Additional file 3), indicating that the enlargement of BTBR $\mathrm{V} 1$ is likely due to an increase in overall cell number. We did, however, observe a non-significant trend towards a lower density of cells in the BTBR strain, potentially indicating that factors other than overall cell number may contribute to the changes in cortical size throughout development, such as changes in intracortical connectivity.

Together, the above results suggest that the change in cortical thickness in BTBR animals occurs without defects in lamination and does not involve changes in neuronal number of specific cortical populations, or alterations in apoptosis, as has previously been suggested in human ASD patients [48]. Rather, it is likely that these changes occur at least partially via a global change in cell number, perhaps via proliferation and/or migration pathways, ultimately maintaining cortical density despite changes in cortical size.

\section{Discussion}

Significant increases in the rate of ASD diagnosis and the cost of treatment over the lifespan of these patients have prompted further research to discover better diagnostic and therapeutic strategies for this disorder. To further this goal, animal models have been developed to investigate the anatomical and functional abnormalities displayed in autistic brains $[4,19,49]$. The BTBR mouse is an inbred strain that is currently used as a model of autism [19,49]. Previous neuroimaging studies have highlighted malformations of white matter connections in this strain $[16,17,21]$. Among these findings, complete absence of the corpus callosum and a significantly reduced hippocampal commissure have been reported [22], as well as ectopic interhemispheric connections [16,21]. However, whether BTBR mice also display disruptions in the formation of functional areas within the cortex is not known. Here, we found that BTBR mice do not exhibit any interhemispheric neocortical connectivity through either normally or ectopically occurring commissures. We also revealed that the positions of both $\mathrm{S} 1$ and V1 are shifted medially and that there are age- and cortical-area-dependent 


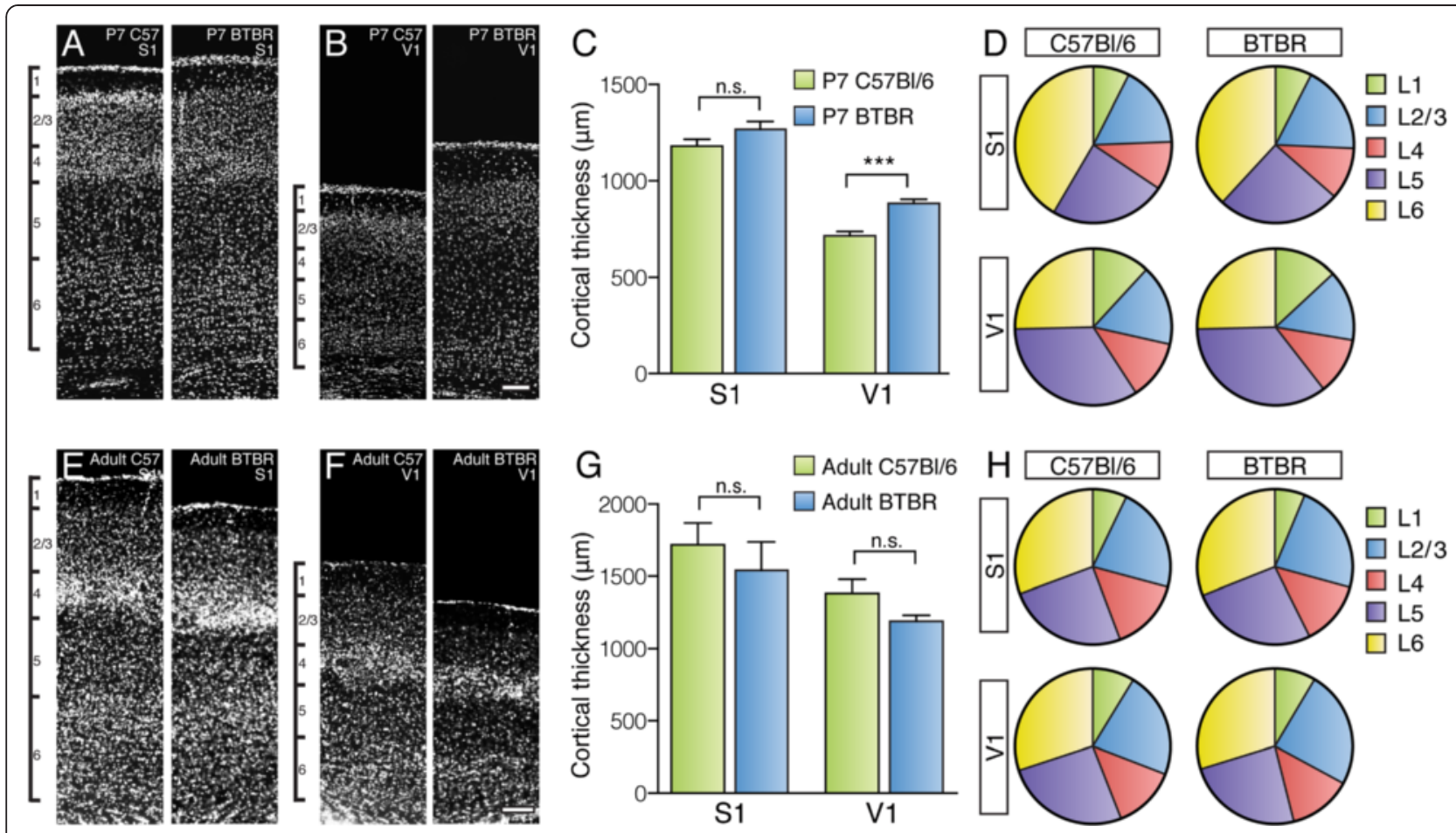

Figure 4 Cortical thickness and layer proportion analysis in C57BI/6 and BTBR mice at different developmental stages. Coronal sections of $\mathrm{C} 57 \mathrm{BI} / 6$ and BTBR brains were stained with nuclear markers, and the thickness of the cortical plate, as well as its composite layers, was measured in P7 and adult animals. Qualitative (A, B) and quantitative (C) analysis reveals a significant increase in cortical thickness of V1, but not S1, at P7 ( $n=7$ animals for each strain, Student's $t$-tests). However, the proportion of layers that comprise the cortical plate is not significantly different between strains ( $n=7$ animals for each strain; thickness of each layer as a percentage of total cortical thickness compared with Student's $t$-tests; (D)). By adulthood, there is no significant difference in cortical thickness between the two strains, although there is a general trend towards a thinner cortex in the BTBR mouse (E-G). The proportion of layers comprising the cortical plate is again unchanged in adulthood between the two strains $(n=6$ animals for each strain; $(\mathbf{H})) .{ }^{* * *} P<0.001$. Scale bar $=100 \mu \mathrm{m}$ for $(\mathrm{A})$ and $(\mathrm{B})$ and $200 \mu \mathrm{m}$ for $(\mathrm{E})$ and $(\mathrm{F}) . \mathrm{BTBR}=\mathrm{BTBR} T+\mathrm{tf} / \mathrm{J}, \mathrm{n} . \mathrm{S} .=$ not significant.

changes in cortical thickness. These results suggest that significant alterations in cortical area patterning and connectivity are present in the BTBR mouse strain that may relate to previously observed sensory or behavioural deficits (for example in social interaction) $[14,19]$.

In marsupials, which lack a corpus callosum, neocortical axons connect interhemispheric areas via the anterior commissure (reviewed in [50]). Similarly, in select patients with complete agenesis of the corpus callosum, it has been suggested that some neocortical axons reroute via the anterior commissure [51]. In the BALB/ cCF mouse strain, in which some animals fail to develop a corpus callosum, the anterior commissure is not enlarged, but the density of axons projecting through this commissure increases, possibly compensating for the loss of callosal axons $[52,53]$. We confirmed that BTBR mice have complete agenesis of the corpus callosum, form longitudinal Probst bundles on either side of the midline and have reduced hippocampal and anterior commissure volume. Similarly, we showed that the anterior and hippocampal commissures are unlikely to compensate for the loss of callosal connections between cortical areas in BTBR mice. This result is particularly interesting in light of a recent study showing that cortical areas can be connected via ectopic projections in the anterior and posterior commissures in acallosal humans [54]. Furthermore, patients with agenesis of the corpus callosum and no anterior commissure display only subtle defects in tests requiring interhemispheric communication [51], indicating that other mechanisms may be involved in such functional compensation.

Areal patterning of the neocortex is a critical event in mammalian brain development. Alterations in the shape and size of one primary cortical area can cause changes in other spatially related areas in the neocortex [28], which could eventually have dramatic effects on brain function, particularly perception and behaviour in adult animals [55-57]. Over the past decade, molecular manipulation of the cortex has demonstrated that neocortical area patterning is initiated by genetic regulation intrinsic to the neocortex and is later refined and maintained by peripheral activity transmitted via thalamocortical axons (extrinsic factors; [28], [58-60]). The correct formation of the barrel field in the BTBR cortex suggests that the gross formation of thalamocortical circuitry occurs normally in BTBR animals, as sensory afferents 


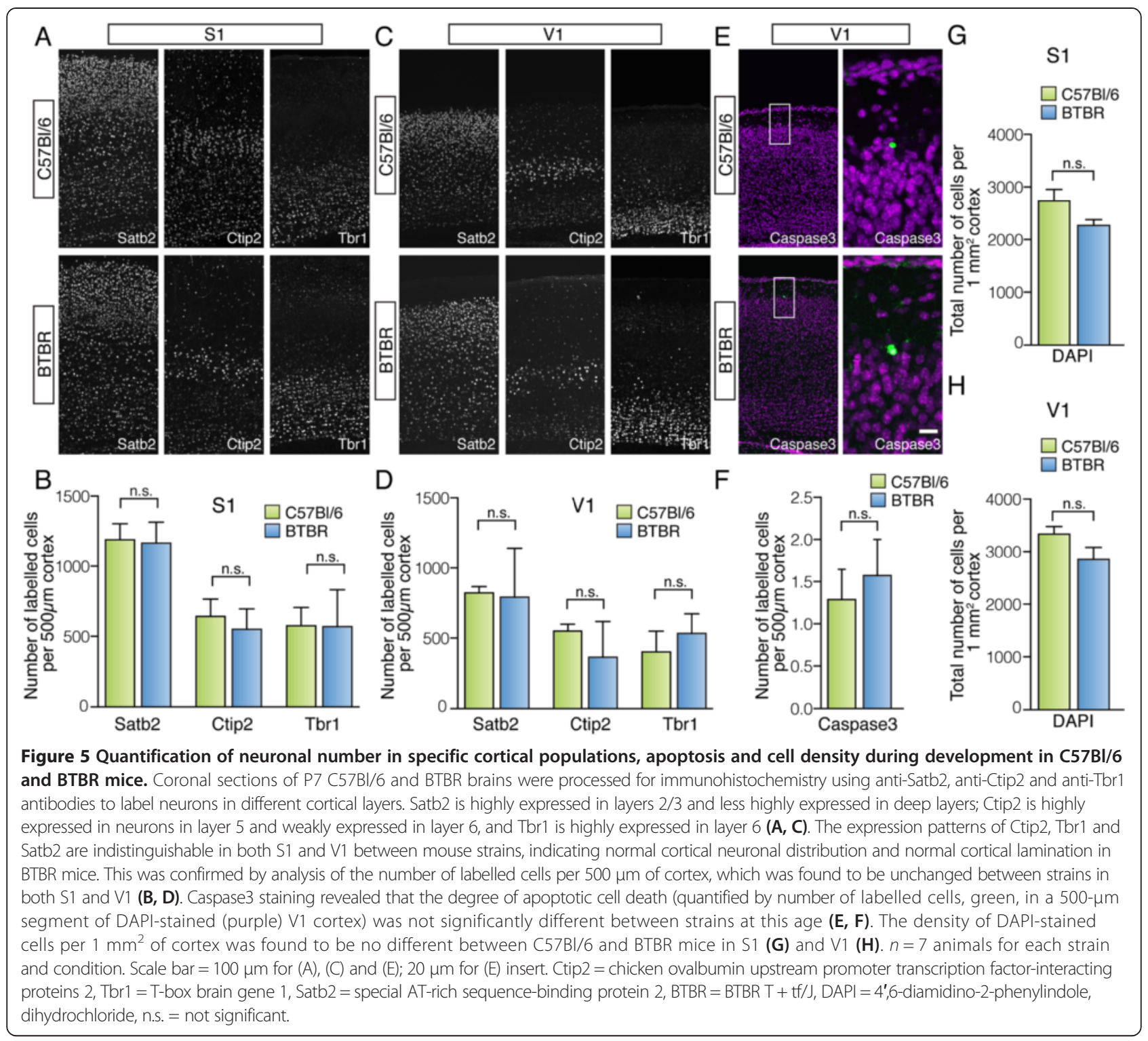

accurately target their correct cortical layer and form characteristic barrel patterns. However, whether the fine topography of this system is maintained remains to be investigated.

Our data demonstrate a significant shift in the position of both $\mathrm{S} 1$ and V1 towards the midline, together with a significant reduction in the size of V1 in BTBR mice compared with $\mathrm{C} 57 \mathrm{Bl} / 6$ mice. Considering the similar size of the neocortex in these two strains at P10, the medial shift of cortical areas could be due to a direct effect of changes in the expression of patterning genes or an indirect effect caused by the simultaneous shrinkage of the medial cortex and expansion of the lateral cortex or changes in white matter organisation. Whatever the causal factor/s, it is tempting to speculate that the observed medial shift in cortical area position in BTBR mice may impact overall cortical function if the space available for adjacent cortical areas associated with higher level processing is reduced. The observed significant reduction in the size of V1 occurs consistently across different stages of development. Further experiments are required to determine if BTBR mice demonstrate deficits in vision as a result of this defect.

Normal cortical lamination in the adult somatosensory cortex has been reported in other strains of acallosal mice, as well as adult mice that have undergone postnatal midline transection $[35,36]$. These studies also revealed altered cortical thickness in these mice, in association with comparatively normal neuronal density in neocortical regions that usually have abundant callosal connections. Although adult cortical thickness does not significantly differ between the two strains, we observed a trend 
towards a thinner cortex in the BTBR mouse, a result that is in agreement with other data showing a widespread decrease in adult cortical thickness in this strain measured by structural MRI [16]. However, we have made the additional finding that a different trend is present during development. At P7, BTBR mice display an increase in cortical thickness in V1, but no change in S1. Similar to the findings in other acallosal models $[35,36]$, we also found that the relative thickness of layers as well as the laminar neuronal populations and degree of apoptosis remains intact despite these alterations. Despite the change in cortical thickness, the total cell density in the cortex is also unchanged between strains, showing that a subtler, global change in the neurogenesis and the migration of newly born neurons in BTBR mice may underlie the observed changes [40]. However, as there is a general trend towards reduced density in the BTBR brains, it is possible that other mechanisms also contribute to changes in cortical thickness. For example, alterations in the intracortical connectivity of BTBR brains (such as a change in the size of dendritic arbours, possibly in response to a loss of interhemispheric connections) may also affect the cortical thickness in this strain.

These results showing changes in the formation of cortical areas in a mouse model of ASD are of potential significance for understanding the basis of this disorder in humans. Recent studies comparing gene expression patterns between ASD patients and controls have shown that the region-specific expression patterns of genes that typically distinguish frontal and temporal cortices, but not the occipital and cerebellar regions, are significantly attenuated in autistic brains $[61,62]$. Moreover, a haplotype analysis of 393 ASD patients in Han Chinese revealed that a haplotype of Wnt2 (rs2896218-rs6950765: G-G), a central nervous system patterning gene, is significantly associated with ASD [63]. Thus, cortical area patterning may be disrupted in ASD patients and may contribute to their aberrant behavioural phenotypes.

One of the most interesting findings of this study involves the variable changes in BTBR animals throughout development. Both the cortical thickness and arealisation analyses revealed a general trend towards larger values in the BTBR strain during development that was then reversed in adulthood. Interestingly, ASD patients also exhibit these changes during development, such as transient childhood increases in brain size and cortical thickness $[64,65]$. These changes are not global, but rather vary between different cortical areas, similar to our observations in BTBR animals [65]. The mechanisms underlying this characteristic of ASD as well as its functional implications remain unclear. Future studies could investigate this aspect of brain development in the BTBR strain as a model for understanding the aetiology and plasticity of ASD more broadly.

\section{Conclusions}

Here, we provide the first evidence that the size, position and thickness of cortical areas are disrupted in the BTBR model of ASD and that these changes occur in varied ways throughout the lifespan of the animal. Using immunohistochemical analyses, we show that these changes are likely due to developmental alterations in total cell number within discrete cortical areas, rather than changes in specific neuronal populations or apoptotic pathways. These anatomical deficits share similarities with trends observed in human ASD patients and may account for some of the autistic-like behavioural abnormalities observed in BTBR mice.

\section{Methods}

\section{Animals}

The BTBR (stock number 002282) line and the C57Bl/6 (stock number 000664) line were both originally sourced from the Jackson Laboratory. All mouse strains were bred at The University of Queensland. Both breeding and experimental protocols were approved by the University of Queensland Animal Ethics Committee and were performed according to the Australian Code of Practice for the Care and Use of Animals for Scientific Purposes. Both female and male mice were used for all adult and postnatal experiments.

\section{Tissue preparation}

For postnatal pups or adult animals, $185 \mathrm{mg} / \mathrm{kg}$ sodium pentobarbitone was injected intraperitoneally. Animals were then transcardially perfused with $0.9 \%$ saline solution $\left(0.9 \% w / v \mathrm{NaCl}\right.$ in $\mathrm{MilliQ}^{\mathrm{TM}}$ water; Millipore, Billerica, USA), followed by freshly prepared $4 \% w / v$ paraformaldehyde (PFA; ProSciTech, Thuringowa Central, Australia) in phosphate-buffered saline (PBS; pH 7.4; Lonza, Basel, Switzerland). The head was removed and post-fixed at $4{ }^{\circ} \mathrm{C}$ in $4 \%$ PFA in PBS until required for tissue processing. For tangential sections, animals were transcardially perfused with $0.9 \%$ saline solution to remove the blood from the brain. The cortices were then dissected and flattened between two slides approximately $1 \mathrm{~mm}$ apart and fixed in $4 \%$ PFA in PBS at $4{ }^{\circ} \mathrm{C}$ for at least $48 \mathrm{~h}$. Following fixation, the flattened cortices were transferred into PBS and maintained at $4{ }^{\circ} \mathrm{C}$ until required for sectioning. Prior to sectioning, brains were blocked in 3\% $w / v$ Difco $^{\text {Tw }}$ Noble agar (Becton, Dickinson and Company, Franklin Lakes, USA) in MilliQ water. Free-floating sections of $50-\mu \mathrm{m}$ thickness were cut using a vibratome (Leica Biosystems, Jurong, Singapore).

\section{MRI data acquisition}

Ex vivo MRI data were acquired using a 16.4 Tesla vertical bore, small animal MRI system (ParaVision v5.0; Bruker Biospin, Madison, USA) and a 15-mm linear, surface 
acoustic wave coil (M2M Imaging, Brisbane, Australia). Brain samples were washed in PBS 4 days prior to scanning and placed in Y06/06 perfluoroether Fomblin oil (Solvay Solexis, Brussels, Belgium). High-resolution $T_{1}$-weighted anatomical images were acquired using a three-dimensional (3D) fast low-angle shot (FLASH) gradient echo sequence at $50-\mu \mathrm{m}$ isotropic resolution, using TR/TE $=50 / 12 \mathrm{~ms}$, flip angle $30^{\circ}$ and 2 averages, with an acquisition time of $1 \mathrm{~h}$. High angular resolution diffusion-weighted imaging (HARDI) was acquired using 3D diffusion-weighted spin-echo images as previously described [66] at $100-\mu \mathrm{m}$ isotropic resolution. Each dataset was composed of two $b 0$ values ( $b$ value of 0 and $\left.5,000 \mathrm{~s} / \mathrm{mm}^{2}, \delta / \Delta=2.5 / 14 \mathrm{~ms}\right), 30$ diffusion-weighted images, 1 average and 1.5 partial-Fourier acceleration factors in the phase dimensions, with an acquisition time of $15 \mathrm{~h}$.

Probabilistic fibre tracking and volumetric measurements The HARDI data were processed using the Constrained Spherical Deconvolution (CSD) model (MRTrix 0.2.9) with $l_{\max }=6$. Fibre tract streamlines were generated using probabilistic tracking with step size 0.01 and curvature 0.04 . To visualise the morphology of the whole brain commissural tracts, 100,000 streamlines were generated in the mid-lateral direction using the mid-sagittal plane as the seeding point. To quantify the major commissural fibre tracts, 10,000 streamlines were generated for each of the anterior commissure, the hippocampal commissure and the corpus callosum from ROIs identified in the mid-sagittal plane through the cortical midline of the fractional anisotropy colour maps.

Volumetric measurements of brain structures were performed by registration of a segmented ex vivo adult C57Bl/ $6 \mathrm{MRI}$ atlas [67] to the anatomical images using the FSL5.0 non-linear registration program (fsl.fmrib.ox.ac.uk/). Results were statistically compared using Student's $t$-tests.

Immunohistochemistry and quantification of cell number Free-floating sections were incubated for $2 \mathrm{~h}$ in $0.9 \% \mathrm{v} / \mathrm{v}$ hydrogen peroxide in blocking solution: 2\% $v / v$ normal goat serum (Vector Laboratories, Burlingame, USA) or normal donkey serum (Jackson Laboratories, Bar Harbor, USA) and 0.2\% v/v Triton-X 100 (Sigma-Aldrich, St. Louis, USA) in PBS. Primary antibodies including rat antiCtip2 monoclonal antibody (1:500; Abcam, Cambridge, UK), rabbit anti-Tbr1 polyclonal antibody (1:500; Santa Cruz Biotechnology, Inc., Dallas, USA), rabbit anti-Satb2 polyclonal antibody (1:500; Abcam, Cambridge, UK), rabbit anti v-Glut2 polyclonal antibody (1:500; Synaptic Systems, Goettingen, Germany) and rabbit anti-cleaved Caspase3 antibody (1:500; Cell Signaling, Danvers, USA) were diluted in blocking solution and applied overnight at room temperature. After $3 \times 20$-min washes with PBS, the sections were incubated with the secondary antibody diluted in $0.2 \% v / v$ Triton-X 100 in PBS for $1 \mathrm{~h}$. The secondary antibodies used were biotinylated donkey-anti-rabbit IgG (1:500; Vector Laboratories, Burlingame, USA) and biotinylated donkey-anti-rat IgG (1:500; Jackson Laboratories, Bar Harbor, USA). The sections were washed with PBS for $3 \times 20 \mathrm{~min}$ and then stained with Alexa Fluor 647conjugated Strepavidin (Invitrogen, Waltham, USA). Where amplification was not needed, donkey-antirabbit Alexa Fluor 488 (1:500; Abcam, Cambridge, UK) secondary antibody was applied for $3 \mathrm{~h}$. After $3 \times 10$-min washes with PBS, the sections were counterstained with DAPI and coverslipped using Prolong gold antifade reagent (Invitrogen, Waltham, USA). After imaging, 500- $\mu \mathrm{m}$-wide regions of the complete neocortex were analysed for the number of positively stained cells. This number was then divided by the area of cortex in which DAPI-stained cells were counted and then multiplied by 1 million to quantify the cellular density as number of cells per $1 \mathrm{~mm}^{2}$ cortex. All values were statistically compared between conditions by Student's $t$-tests or Mann-Whitney tests $(n=7$ animals for each strain in all conditions).

\section{Image acquisition}

Brightfield imaging was performed with a Zeiss upright Axio-Imager Z1 microscope fitted with an Axio-Cam HRc camera. Confocal fluorescent images were acquired as single $0.6-\mu \mathrm{m}$-thick optical sections using a Zeiss inverted Axio-Observer fitted with a W1 Yokogawa spinning disk module and Hamamatsu Flash4.0 sCMOS camera and Slidebook 5.5 software. Images were pseudocoloured to permit overlay and then were cropped, sized and contrast-brightness enhanced for presentation with Adobe Photoshop software.

\section{Quantification of cortical thickness in BTBR and C57BI/6 mice}

DAPI or haematoxylin staining was performed on $50-\mu \mathrm{m}$ coronal sections from adult BTBR and $\mathrm{C} 57 \mathrm{Bl} / 6$ mouse brains ( $n=6$ for each strain; equal numbers of DAPI or haematoxylin staining for each condition) to reveal gross cortical anatomy. For haematoxylin staining, sections were first sequentially mounted onto gelatin-coated SuperFrostPlus slides (Menzel-Gläser, Brunswick, Germany) and allowed to air dry for approximately $30 \mathrm{~min}$. Sections were then hydrated with PBS and bathed in Mayer's haematoxylin (Sigma-Aldrich, St. Louis, USA) for $5 \mathrm{~min}$. The reaction was then stopped by rinsing the sections in tap water for 5 min, after which they were immersed sequentially in a series of graded ethanols, followed by xylene, then coverslipped with DPX mounting medium. Following imaging of the slides, measurements of cortical 
thickness and layer size were conducted in the centre of $\mathrm{S} 1$ and V1 in comparable coronal sections from each animal of both mouse strains. Quantification at P7 was performed on DAPI-stained sections resulting from the previously described immunohistochemical staining $(n=7$ for each strain). For layer proportion analysis, the absolute thickness of each layer was converted into a proportion of the total cortical thickness for that single brain and then each layer was statistically compared between strains. Results were statistically compared with Student's $t$-tests.

\section{Quantification of relative size and position of cortical areas in $\mathrm{BTBR}$ and $\mathrm{C} 57 \mathrm{BI} / 6$ mice}

Tangential sections of P7, P10 and P22 cortices (stained for v-Glut2) of both mouse strains were imaged and then unbiased measurements were obtained from deidentified images for strain. Following analysis, images were then reassigned their strain genotype based on a numerical code. The PMBSF, V1 and the whole neocortex in both hemispheres in $\mathrm{C} 57 \mathrm{Bl} / 6$ and BTBR mice were manually outlined using ImageJ (National Institutes of Health). We defined the longest diameter of the flattened neocortex (distinguished from the olfactory cortex by the bordering rhinal fissure) as the 'length' of the neocortex, and the 'width' was measured on the axis perpendicular to this. Next, the areas of the PMBSF, V1 and the whole neocortex were measured. The third barrel in row $\mathrm{C}$ (the $\mathrm{C} 3$ barrel) was then used as a central point for the PMBSF in the analysis of the relative position of the PMBSF, while the apex of the v-Glut2-stained area of V1 was used to identify the relative position of V1. Using these points, we measured the anterior and medial positions of the centre of the $\mathrm{C} 3$ barrel and the position of the most rostral tip of V1. The relative positions of the PMBSF and V1 were calculated by normalising their anterior length or medial length according to the total length or width of the neocortex, respectively. All results were then compared between strains for each age using a Student's $t$-test.

\section{Additional files}

Additional file 1: Table S1. Cortical area measurements as graphed in Figure 3. Table of mean, SEM and $P$ values for the graphical data in Figure 3.

Additional file 2: Table S2. Cortical thickness and layer proportion as graphed in Figure 4. Table of mean, SEM and $P$ values for the graphical data in Figure 4.

Additional file 3: Table S3. Transcription factor, Caspase3 and DAPI cell counts as graphed in Figure 5. Table of mean, SEM and $P$ values for the graphical data in Figure 5.

\section{Abbreviations}

3D: three-dimensional; ASD: autism spectrum disorder; BTBR: BTBR T + tj/ CSD: Constrained Spherical Deconvolution; Ctip2: chicken ovalbumin upstream promoter transcription factor-interacting proteins 2; DAPI: 4',6-diamidino-2phenylindole, dihydrochloride; FLASH: fast low-angle shot; HARDI: high angular resolution diffusion-weighted imaging; MRI: magnetic resonance imaging; PBS: phosphate-buffered saline; PFA: paraformaldehyde; PMBSF: posterior medial barrel subfield; ROI: region of interest; S1: primary somatosensory cortex; Satb2: special AT-rich sequence-binding protein 2; Tbr1: T-box brain gene 1; V1: primary visual cortex; v-Glut2: vesicular-glutamate transporter 2; Wnt2: wingless-type MMTV integration site family, member 2.

\section{Competing interests}

The authors declare that they have no competing interests.

\section{Authors' contributions}

LRF, SL and IG participated in the design of the study, carried out the majority of experiments, prepared the display items and wrote the manuscript. NK and RXM performed the diffusion MRI and some of the tractography. NK performed the analysis on the streamline differences and contributed to the preparation of display items and the manuscript. SM contributed to the cortical thickness analyses. LJR conceived the study and participated in its design, coordinated the experiments and wrote the manuscript. All authors read and approved the final manuscript.

\section{Authors' information}

Laura R Fenlon and Sha Liu are co-first authors.

\section{Acknowledgements}

This research was supported by the National Health and Medical Research Council (NHMRC), Australia project grants 1043045 and 1029975. LRF is supported by an Australian Post-graduate Award. SL was supported by a PhD Scholarship from the Chinese Academy of Sciences with supplemental funding from the Queensland Brain Institute. LJR is supported by a Principal Research Fellowship from the NHMRC. The content of this paper is solely the responsibility of the authors and does not necessarily represent the official views of the NHMRC. We thank the Queensland State Government for supporting the operation of the 16.4 T scanner through the Queensland NMR Network. We thank Ilse Buttiens and Rowan Tweedale for assistance in the preparation of this manuscript.

\section{Author details}

${ }^{1}$ Queensland Brain Institute, The University of Queensland, Building 79, St Lucia Campus, Brisbane, QLD 4072, Australia. ${ }^{2}$ Centre for Advanced Imaging, The University of Queensland, Brisbane, QLD 4072, Australia. ${ }^{3}$ The School of Biomedical Sciences, The University of Queensland, St Lucia Campus, Brisbane, QLD 4072, Australia. ${ }^{4}$ Current address: UQ Centre for Clinical Research, The University of Queensland, Royal Brisbane \& Women's Hospital Campus, Brisbane, Queensland 4029, Australia.

Received: 7 October 2014 Accepted: 27 February 2015

Published online: 03 April 2015

\section{References}

1. Buxbaum JD, Hof PR. The neuroscience of autism spectrum disorders. 1st ed. Netherlands: Amsterdam: Elsevier/Academic Press; 2013. p. 2013.

2. Betancur $\mathrm{C}$. Etiological heterogeneity in autism spectrum disorders: more than 100 genetic and genomic disorders and still counting. Brain Res. 2011;1380:42-77

3. Hallmayer J, Cleveland S, Torres A, Phillips J, Cohen B, Torigoe T, et al. Genetic heritability and shared environmental factors among twin pairs with autism. Arch Gen Psychiatry. 2011;68(11):1095-102.

4. Persico AM, Bourgeron T. Searching for ways out of the autism maze: genetic, epigenetic and environmental clues. Trends Neurosci. 2006;29(7):349-58.

5. Butrimaviciute R, Grieve A. Carers' experiences of being exposed to challenging behaviour in services for autism spectrum disorders. Autism. 2014;18(8):882-90.

6. Hall L, Kelley E. The contribution of epigenetics to understanding genetic factors in autism. Autism. 2014;18(8):872-81.

7. Gesundheit B, Rosenzweig JP, Naor D, Lerer B, Zachor DA, Prochazka V, et al. Immunological and autoimmune considerations of autism spectrum disorders. J Autoimmun. 2013;44:1-7. 
8. Evangeliou A, Vlachonikolis I, Mihailidou H, Spilioti M, Skarpalezou A, Makaronas N, et al. Application of a ketogenic diet in children with autistic behavior: pilot study. J Child Neurol. 2003;18(2):113-8.

9. Manzardo AM, Henkhaus R, Dhillon S, Butler MG. Plasma cytokine levels in children with autistic disorder and unrelated siblings. Int J Dev Neurosci. 2012;30(2):121-7.

10. Stanfield AC, McIntosh AM, Spencer MD, Philip R, Gaur S, Lawrie SM. Towards a neuroanatomy of autism: a systematic review and meta-analysis of structural magnetic resonance imaging studies. Eur Psychiatry. 2008;23(4):289-99.

11. Via E, Radua J, Cardoner N, Happe F, Mataix-Cols D. Meta-analysis of gray matter abnormalities in autism spectrum disorder: should Asperger disorder be subsumed under a broader umbrella of autistic spectrum disorder? Arch Gen Psychiatry. 2011;68(4):409-18.

12. Bellani M, Calderoni S, Muratori F, Brambilla P. Brain anatomy of autism spectrum disorders I. Focus Corpus Callosum Epidemiol Psychiatr Sci. 2013;22(3):217-21.

13. Vidal CN, Nicolson R, Boire JY, Barra V, DeVito TJ, Hayashi KM, et al. Three-dimensional mapping of the lateral ventricles in autism. Psychiatry Res. 2008;163(2):106-15.

14. Moy SS, Nadler JJ, Young NB, Perez A, Holloway LP, Barbaro RP, et al. Mouse behavioral tasks relevant to autism: phenotypes of 10 inbred strains. Behav Brain Res. 2007;176(1):4-20.

15. Silverman JL, Yang M, Lord C, Crawley JN. Behavioural phenotyping assays for mouse models of autism. Nat Rev Neurosci. 2010;11(7):490-502.

16. Dodero L, Damiano M, Galbusera A, Bifone A, Tsaftsaris SA, Scattoni ML, et al. Neuroimaging evidence of major morpho-anatomical and functional abnormalities in the BTBR T + TF/J mouse model of autism. PLoS One. 2013;8(10):e76655.

17. Ellegood J, Babineau BA, Henkelman RM, Lerch JP, Crawley JN. Neuroanatomical analysis of the BTBR mouse model of autism using magnetic resonance imaging and diffusion tensor imaging. Neuroimage. 2013;70:288-300

18. Schwartzer JJ, Careaga M, Onore CE, Rushakoff JA, Berman RF, Ashwood P. Maternal immune activation and strain specific interactions in the development of autism-like behaviors in mice. Transl Psychiatry. 2013;3:e240.

19. McFarlane HG, Kusek GK, Yang M, Phoenix JL, Bolivar VJ, Crawley JN. Autism-like behavioral phenotypes in BTBR T+tf/J mice. Genes Brain Behav. 2008;7(2):152-63.

20. Scattoni ML, Gandhy SU, Ricceri L, Crawley JN. Unusual repertoire of vocalizations in the BTBR T+tf/J mouse model of autism. PLoS One. 2008;3(8):e3067.

21. Miller VM, Gupta D, Neu N, Cotroneo A, Boulay CB, Seegal RF. Novel inter-hemispheric white matter connectivity in the BTBR mouse model of autism. Brain Res. 2013;1513:26-33.

22. Wahlsten $D$, Metten $P$, Crabbe JC. Survey of 21 inbred mouse strains in two laboratories reveals that BTBR T/+ tf/tf has severely reduced hippocampal commissure and absent corpus callosum. Brain Res. 2003;971(1):47-54.

23. Paul LK, Corsello C, Kennedy DP, Adolphs R. Agenesis of the corpus callosum and autism: a comprehensive comparison. 2014

24. Jones-Davis DM, Yang M, Rider E, Osbun NC, da Gente GJ, Li J, et al. Quantitative trait loci for interhemispheric commissure development and social behaviors in the BTBR T(+) tf/J mouse model of autism. PLoS One. 2013;8(4):e61829.

25. Yang M, Clarke AM, Crawley JN. Postnatal lesion evidence against a primary role for the corpus callosum in mouse sociability. Eur J Neurosci. 2009;29(8):1663-77.

26. Rubenstein $J$ L. Annual research review: development of the cerebral cortex: implications for neurodevelopmental disorders. J Child Psychol Psychiatry. 2011;52(4):339-55.

27. O'Leary DD, Sahara S. Genetic regulation of arealization of the neocortex. Curr Opin Neurobiol. 2008;18(1):90-100.

28. O'Leary DD, Chou SJ, Sahara S. Area patterning of the mammalian cortex. Neuron. 2007;56(2):252-69.

29. Probst M. The structure of complete dissolving corpus callosum of the cerebrum and also the microgyry and heterotropy of the grey substance. Arch Psychiatr Nervenkr. 1901;34:709-86.

30. Lee SK, Mori S, Kim DJ, Kim SY, Kim SY, Kim DI. Diffusion tensor MR imaging visualizes the altered hemispheric fiber connection in callosal dysgenesis. AJNR Am J Neuroradiol. 2004;25(1):25-8.

31. Tovar-Moll F, Moll J, de Oliveira-Souza R, Bramati I, Andreiuolo PA, Lent R. Neuroplasticity in human callosal dysgenesis: a diffusion tensor imaging study. Cereb Cortex. 2007;17(3):531-41.
32. Ren T, Zhang J, Plachez C, Mori S, Richards LJ. Diffusion tensor magnetic resonance imaging and tract-tracing analysis of Probst bundle structure in Netrin1- and DCC-deficient mice. J Neurosci. 2007;27(39):10345-9.

33. Sforazzini F, Bertero A, Dodero L, David G, Galbusera A, Scattoni ML et al. Altered functional connectivity networks in acallosal and socially impaired BTBR mice. Brain Struct Funct. 2014;doi:10.1007/s00429-014-0948-9.

34. Ozaki HS, Iwahashi K, Shimada M. Ipsilateral corticocortical projections of fibers which course within Probst's longitudinal bundle seen in the brains of mice with congenital absence of the corpus callosum: a study with the horseradish peroxidase technique. Brain Res. 1989;493(1):66-73.

35. Abreu-Villaca Y, Silva WC, Manhaes AC, Schmidt SL. The effect of corpus callosum agenesis on neocortical thickness and neuronal density of BALB/CCF mice. Brain Res Bull. 2002;58(4):411-6.

36. Ribeiro-Carvalho A, Manhaes AC, Abreu-Villaca Y, Filgueiras CC. Early callosal absence disrupts the establishment of normal neocortical structure in Swiss mice. Int J Dev Neurosci. 2006;24(1):15-21.

37. Liguz-Lecznar M, Skangiel-Kramska J. Vesicular glutamate transporters VGLUT1 and VGLUT2 in the developing mouse barrel cortex. Int J Dev Neurosci. 2007;25(2):107-14.

38. Nahmani M, Erisir A. VGluT2 immunochemistry identifies thalamocortical terminals in layer 4 of adult and developing visual cortex. J Comp Neurol. 2005;484(4):458-73.

39. Jan TA, Lu L, Li CX, Williams RW, Waters RS. Genetic analysis of posterior medial barrel subfield (PMBSF) size in somatosensory cortex (SI) in recombinant inbred strains of mice. BMC Neurosci. 2008;9:3.

40. Yang K, Cao F, Sheikh AM, Malik M, Wen G, Wei H, et al. Up-regulation of Ras/Raf/ERK1/2 signaling impairs cultured neuronal cell migration, neurogenesis, synapse formation, and dendritic spine development. Brain Struct Funct. 2013;218(3):669-82.

41. Stephenson DT, O'Neill SM, Narayan S, Tiwari A, Arnold E, Samaroo HD, et al Histopathologic characterization of the BTBR mouse model of autistic-like behavior reveals selective changes in neurodevelopmental proteins and adult hippocampal neurogenesis. Mol Autism. 2011;2(1):7.

42. Alcamo EA, Chirivella L, Dautzenberg M, Dobreva G, Farinas I, Grosschedl R, et al. Satb2 regulates callosal projection neuron identity in the developing cerebral cortex. Neuron. 2008:57(3):364-77.

43. Britanova O, de Juan RC, Cheung A, Kwan KY, Schwark M, Gyorgy A, et al. Satb2 is a postmitotic determinant for upper-layer neuron specification in the neocortex. Neuron. 2008;57(3):378-92.

44. Tashiro K, Teissier A, Kobayashi N, Nakanishi A, Sasaki T, Yan K, et al. A mammalian conserved element derived from SINE displays enhancer properties recapitulating Satb2 expression in early-born callosal projection neurons. PLoS One. 2011;6(12):e28497.

45. McKenna WL, Betancourt J, Larkin KA, Abrams B, Guo C, Rubenstein JL, et al. Tbr1 and Fezf2 regulate alternate corticofugal neuronal identities during neocortical development. J Neurosci. 2011;31(2):549-64.

46. Arlotta P, Molyneaux BJ, Chen J, Inoue J, Kominami R, Macklis JD. Neuronal subtype-specific genes that control corticospinal motor neuron development in vivo. Neuron. 2005;45(2):207-21.

47. Hevner RF, Shi L, Justice N, Hsueh Y, Sheng M, Smiga S, et al. Tbr1 regulates differentiation of the preplate and layer 6. Neuron. 2001;29(2):353-66.

48. Fatemi SH, Halt AR. Altered levels of $\mathrm{BCl} 2$ and p53 proteins in parietal cortex reflect deranged apoptotic regulation in autism. Synapse. 2001;42(4):281-4.

49. Meyza KZ, Defensor EB, Jensen AL, Corley MJ, Pearson BL, Pobbe RL, et al. The BTBR T+ tf/J mouse model for autism spectrum disorders-in search of biomarkers. Behav Brain Res. 2013;251:25-34.

50. Suárez R, Gobius I, Richards L. Evolution and development of interhemispheric connections in the vertebrate forebrain. Front Hum Neurosci. 2014;8:497.

51. Fischer M, Ryan SB, Dobyns WB. Mechanisms of interhemispheric transfer and patterns of cognitive function in acallosal patients of normal intelligence. Arch Neurol. 1992;49(3):271-7.

52. Schmidt SL, Caparelli-Daquer EM. The effects of total and partial callosal agenesis on the development of morphological brain asymmetries in the BALB/CCF mouse. Exp Neurol. 1989;104(2):172-80.

53. Livy DJ, Schalomon PM, Roy M, Zacharias MC, Pimenta J, Lent R, et al. Increased axon number in the anterior commissure of mice lacking a corpus callosum. Exp Neurol. 1997;146(2):491-501.

54. Tovar-Moll F, Monteiro M, Andrade J, Bramati IE, Vianna-Barbosa R, Marins T, et al. Structural and functional brain rewiring clarifies preserved interhemispheric 
transfer in humans born without the corpus callosum. Proc Natl Acad Sci. 2014;111(21):7843-8.

55. Huang Z, Kawase-Koga Y, Zhang S, Visvader J, Toth M, Walsh CA, et al. Transcription factor $\mathrm{Lmo} 4$ defines the shape of functional areas in developing cortices and regulates sensorimotor control. Dev Biol. 2009;327(1):132-42.

56. Leingartner A, Thuret S, Kroll TT, Chou SJ, Leasure JL, Gage FH, et al. Cortical area size dictates performance at modality-specific behaviors. Proc Natl Acad Sci U S A. 2007;104(10):4153-8.

57. O'Leary DD, Chou SJ, Hamasaki T, Sahara S, Takeuchi A, Thuret S, et al. Regulation of laminar and area patterning of mammalian neocortex and behavioural implications. Novartis Found Symp. 2007;288:141-59. discussion 159-164, 276-181.

58. Zembrzycki A, Chou S-J, Ashery-Padan R, Stoykova A, O'Leary DDM. Sensory cortex limits cortical maps and drives top-down plasticity in thalamocortical circuits. Nat Neurosci. 2013;16(8):1060-7.

59. Chou S-J, Babot Z, Leingärtner A, Studer M, Nakagawa Y, O'Leary DDM. Geniculocortical input drives genetic distinctions between primary and higher-order visual areas. Science. 2013;340(6137):1239-42.

60. Vue TY, Lee M, Tan YE, Werkhoven Z, Wang L, Nakagawa Y. Thalamic control of neocortical area formation in mice. J Neurosci. 2013;33(19):8442-53.

61. Ginsberg MR, Rubin RA, Natowicz MR. Patterning of regional gene expression in autism: new complexity. Sci Rep. 2013;3:1831.

62. Voineagu I, Wang $X$, Johnston $P$, Lowe JK, Tian $Y$, Horvath $S$, et al. Transcriptomic analysis of autistic brain reveals convergent molecular pathology. Nature. 2011;474(7351):380-4.

63. Chien YL, Wu YY, Chiu YN, Liu SK, Tsai WC, Lin Pl, et al. Association study of the CNS patterning genes and autism in Han Chinese in Taiwan. Prog Neuropsychopharmacol Biol Psychiatry. 2011:35(6):1512-7.

64. Redcay E, Courchesne E. When is the brain enlarged in autism? A meta-analysis of all brain size reports. Biol Psychiatry. 2005;58(1):1-9.

65. Zielinski BA, Prigge MBD, Nielsen JA, Froehlich AL, Abildskov TJ, Anderson JS, et al. Longitudinal changes in cortical thickness in autism and typical development, vol. 137. 2014.

66. Moldrich RX, Pannek K, Hoch R, Rubenstein JL, Kurniawan ND, Richards LJ. Comparative mouse brain tractography of diffusion magnetic resonance imaging. Neuroimage. 2010;51(3):1027-36.

67. Ma Y, Hof PR, Grant SC, Blackband SJ, Bennett R, Slatest L, et al. A three-dimensional digital atlas database of the adult C57BL/6 J mouse brain by magnetic resonance microscopy. Neuroscience. 2005;135(4):1203-15.

\section{Submit your next manuscript to BioMed Central and take full advantage of:}

- Convenient online submission

- Thorough peer review

- No space constraints or color figure charges

- Immediate publication on acceptance

- Inclusion in PubMed, CAS, Scopus and Google Scholar

- Research which is freely available for redistribution 